\title{
Occurrence and quality of anticoagulant treatment of chronic atrial fibrillation in primary health care in Sweden: a retrospective study on electronic patient records Gunnar H Nilsson*1 and Ingela Björholt ${ }^{2}$
}

Address: ${ }^{1}$ Department of Medicine, Research Unit of General Practice, Karolinska Institutet, Stockholm, Sweden and ${ }^{2}$ Institute of Surgical Sciences, Göteborg University, Sahlgrenska University Hospital, Göteborg, Sweden

Email: Gunnar H Nilsson* - gunnar.nilsson@nlpo.sll.se; Ingela Björholt - ingela.bjorholt@telia.com

* Corresponding author

Published: 09 February 2004

BMC Clinical Pharmacology 2004, 4:I
Received: 20 October 2003

Accepted: 09 February 2004

This article is available from: http://www.biomedcentral.com/I472-6904/4/I

(C) 2004 Nilsson and Björholt; licensee BioMed Central Ltd. This is an Open Access article: verbatim copying and redistribution of this article are permitted in all media for any purpose, provided this notice is preserved along with the article's original URL.

\begin{abstract}
Background: Chronic atrial fibrillation is a prevalent cardiac disorder. The literature indicates varying proportions of those treated with anticoagulants, and varying intensity of anticoagulation. Electronic patient records are providing us with clinical data concerning management of anticoagulant treatment in real-life practice that is useful for audits. We aimed to assess warfarin treatment for chronic atrial fibrillation in primary health care with regard to prevalence, incidence, the proportion treated and the quality of anticoagulation control.
\end{abstract}

Methods: Five primary health care centres in Stockholm with a registered population of 75I46 participated in a one-year retrospective study of electronic patient records up until May 2000. All patients over 18 years of age with an encounter labelled 'Atrial fibrillation' were identified, and all records of patients on warfarin treatment were manually reviewed. Main outcome measures were number of patients with chronic atrial fibrillation, number of patients on wafarin treatment, and time within the therapeutic prothrombin range.

Results: In total, 419 patients had chronic atrial fibrillation, giving a prevalence of $0.60 \%$ (ageadjusted $0.62 \%$ ), the age group 65 years or older accounted for $91.6 \%$, and $50.1 \%$ were women. Out of these, $50.4 \%$ (2II patients) were established on warfarin treatment for chronic atrial fibrillation $(0.28 \%$ of the population), and there was a predominance of men $(p=0.02)$. Fifty-four patients started treatment with warfarin for chronic atrial fibrillation ( $0.07 \%$ of the population). Among 25 randomly selected patients on established treatment, the proportion of time within the therapeutic range was $70.2 \%$. Among 24 randomly selected patients starting treatment, the proportion of time with therapeutic values was $54.2 \%$ and $66.9 \%$ the first and second months of treatment, respectively.

Conclusions: Chronic atrial fibrillation is common among the elderly in primary health care, and about half of these patients are treated with warfarin. It appears to be under-diagnosed, and may also be under-treated. About two thirds of treatment time is spent within the therapeutic range, and further improvement of the quality of anticoagulation control with warfarin may therefore be hard to achieve. 


\section{Background}

Chronic atrial fibrillation (CAF) is an increasingly common cardiac disorder, with a prevalence of $0.9-1.2 \%$ in the population $[1,2]$, and it increases with age to $4.7 \%$ in persons aged 65 years or older [3]. It is associated with an annual incidence of thromboembolic stroke of 2-6\% [4]. Oral anticoagulant drugs, i.e. vitamin $\mathrm{K}$ antagonists, have been shown in well-designed clinical trials to have antithrombotic efficacy in the prevention of embolic stroke in patients with CAF, and they are medically and economically justified $[4,5]$.

Warfarin is the standard anticoagulant drug used in Sweden. It is an efficacious anticoagulant, but it has a narrow therapeutic range. A prothrombin time corresponding to the International Normalized Ratio (INR) target of 2.5 (range 2-3) is recommended for most indications. The anticoagulant response to warfarin is influenced by many drug interactions and it is also affected by genetic and significant environmental variability. A large number of studies have demonstrated that the risk of bleeding complications during treatment with warfarin increases drastically with an INR above the target value, and that the antithrombotic effectiveness disappears with low INR values [6-8]. There is a relationship between the effectiveness of warfarin and the proportion of time within the therapeutic range, and such estimates have therefore been used as a measure of the quality of anticoagulation treatment [9]. Several studies indicate that CAF is the most common treatment diagnosis for warfarin $[10,11]$. The treatment is considered fairly safe [12], although bleeding complications do occur [13]. The number of fatal or major bleeding complications in clinical practice is about $1.7 \%$ per patient-year [14]. Monitoring is frequently managed by general practitioners (GP) [15]. There is ongoing discussion concerning whether efficiency and safety can be kept as low in primary health care (PHC) as at special clinics for anticoagulation services.

The proportion of patients with CAF that are treated with warfarin in primary health care settings is increasing [2], but was shown in recent studies to vary widely, from 2997\% [2,16-18]. A significant underuse of warfarin has been reported $[3,16,19]$. The proportion of CAF patients eligible for warfarin treatment varies from 41-61\% depending on the criteria used $[13,20]$. Contraindications for warfarin treatment have been reported in $11-18 \%$ of these patients $[21,22]$.

The literature indicates a variable level of anticoagulation intensity in real-life settings, with $43-81 \%$ of tests within the therapeutic range [23-26], and the proportion of time spent within the therapeutic range varying from $47-51 \%$ $[22,27]$. Few studies have focused on monitoring in rou- tine medical care, which is the predominant model of care in many countries.

Patients on warfarin treatment in Stockholm are now almost universally managed in PHC. Electronic patient records (EPR) are currently used by almost all GPs in the area, providing us with clinical data that is useful for research. The general objective of this study was to study the prevalence of CAF and its treatment with warfarin in everyday clinical practice in PHC in a representative sample of clinics. The specific objective was to assess prevalence, incidence, the proportion treated and the quality of anticoagulation control.

\section{Methods \\ Selection of PHC centres}

In order to compensate for local variations regarding the population, we invited one PHC centre from each of the five different health care districts in Stockholm County. The EPR included the entire medical record and no paper records were used. In each PHC centre one GP was appointed as investigator. The total registered population (calculated from a population registry maintained for each GP) of the participating GPs comprised 75146 individuals at the end of the study period.

\section{Identifying patients}

The initial selection criterion was all patients over 18 years of age with an encounter labelled 'Atrial fibrillation' (code I48- in the Swedish primary care version of ICD-10), during a 12-month study period (June 1999 to May 2000). The diagnosis of CAF was based on a clinical diagnosis recorded by the GP, including persistent (i.e. en episode of atrial fibrillation that has not reverted spontaneously to sinus rhythm) and permanent atrial fibrillation (i.e. when attempts at restoration of sinus rhythm have failed or where the probability of successful cardio version is considered so low that no attempt is made) [28]. CAF is distinguished from 'Paroxysmal tachycardia' (code I47-, including episodes of atrial fibrillation which are self-terminating) in the current classification. The second selection criterion was all patients on warfarin treatment. This was further specified as patients who were monitored with INR values and whose daily dosages of warfarin were ordered by a GP at the PHC centre.

\section{Data collection}

The EPR systems were searched for code I48-, INR, age and gender through their statistical modules for primary data retrieval. The investigator thereafter manually reviewed all EPRs including INR. Patients who had received a minimum of 30 consecutive days of treatment during the study period were included in the evaluation of proportion treated and the quality of anticoagulation control. We evaluated two groups of these patients, those with 1) 
Table I: Registered population, prevalence of chronic atrial fibrillation (CAF), patients established on warfarin treatment, and proportion treated, at five primary health care centres.

\begin{tabular}{|c|c|c|c|c|c|c|c|c|}
\hline Age group & & $<45$ & $45-64$ & $65-74$ & $75-84$ & $85+$ & Total & Women \\
\hline Registered population & $N$ & 45294 & 18539 & 5125 & 4470 & 1718 & 75146 & 38851 \\
\hline Diagnosed CAF $(n=419)$ & $\%$ & $<0.01$ & 0.19 & 2.19 & 3.94 & 5.59 & 0.60 & 0.54 \\
\hline Age adjusted & & & & & & & 0.62 & 0.60 \\
\hline Established treatment $(\mathrm{n}=21 \mathrm{I})$ & $\%$ & $<0.01$ & 0.16 & 1.35 & 2.04 & 1.05 & 0.28 & 0.23 \\
\hline Age adjusted & & & & & & & 0.28 & 0.25 \\
\hline Proportion treated & $\%$ & - & 85.7 & 61.6 & 51.7 & 18.8 & 50.4 & $42.2 *$ \\
\hline
\end{tabular}

* Significantly more men $(p=0.02)$

established treatment, and those who 2) started treatment during the study period. For the first group, all patients with established warfarin treatment for CAF as the only treatment diagnosis, or one of several treatment diagnoses, were identified. The follow-up period for each of these patients was 12 months for two centres and three months for three centres, due to variable resources at the centres. The follow-up continued until the last day of the period or the date of discontinuation. For the second group, all patients were identified who started warfarin treatment for CAF as the only indication, or one of several indications, during the study period. The follow-up period was 90 days, starting with the first day of treatment. For both these groups we randomly selected (using a table of random numbers) five patients from each health care centre (a total of 25 patients per group), and they were subjected to a more detailed follow-up of INR monitoring. For the selected patients (as described above), information was collected concerning start date for treatment, and data from each monitoring episode (i.e. where PT was monitored and dosages given) including date and INR value. The monitoring of anticoagulant treatment was performed using INR, and the standard range was from 2.0 to 3.0 INR.

\section{Statistical analysis}

The data were analysed using the SPSS ${ }^{\varpi}$ software programme. The time spent in the INR target range was estimated using linear interpolation [29], which assumes that the INR between two consecutive measurements varies linearly, including only INR values obtained at intervals of eight weeks or less. Independent two-sample t-tests were used to compare interval scaled variables. The Chisquare test was used to test the distribution of cross-classified nominal variables. Ninety-five percent confidence intervals (CI) were used.

\section{Ethical considerations}

This study was approved by the regional ethics committee at Karolinska Institutet.

\section{Results}

\section{Occurrence and proportion treated}

The total registered population was 75 146. In total, 419 patients had CAF, giving a prevalence of $0.60 \%$ (ageadjusted $0.62 \%$ ), and $50.1 \%$ were women (Table 1 ). The age group 65 years or older accounted for $91.6 \%$ of patients with $\mathrm{CAF}$, and $3.35 \%$ in the population. The prevalence of CAF increased with increasing age, from $0.19 \%$ in the age group $45-64$ years, to $5.59 \%$ in the age group 85 years or older. Out of these, 211 patients were on warfarin treatment for $\mathrm{CAF}$, from 20 to 76 patients at each PHC centre, 122 men and 89 women, and the mean age was 73.7 (CI 95\% 72.4; 75.1) (Table 1). Men were significantly predominant $(\mathrm{P}=0.02)$, accounting for $57.8 \%$ (CI 95\% 51.1; 64.4). The proportion treated with warfarin was $50.4 \%$, declining from $85.7 \%$ in the age group $45-64$ years, to $18.8 \%$ in the age group 85 years or older. The number of patients who started warfarin treatment for CAF at the participating PHC centres was 54, accounting for $25.6 \%$ of patients with CAF who were not on warfarin treatment, and for $0.07 \%$ of the population.

\section{Anticoagulation control}

Among the 25 randomly selected patients established on warfarin treatment, the median start year for the treatment was 1997. Indications for warfarin treatment besides CAF were found for five patients: prosthetic valve (three patients), deep venous thrombosis (one), and cardiac infarction (one). A total of 216 INR monitoring episodes were identified. INR monitoring was done on average 1.3 times per month. The individual range for INR values was 2.0 to 3.0 INR for 24 of the patients, while one patient had a lower range ( 1.7 to 2.5 ). The proportion of time within the therapeutic range was $70.2 \%$ (Table 2), and the proportion of values within the therapeutic range was $71.5 \%$. Values with a high bleeding risk (INR > 6.0) were not found.

In the 25 randomly selected patients for whom warfarin treatment was initiated during the study period, no treatment diagnosis other than CAF was found. Data concern- 
Table 2: Proportion of patient time (95\% confidence intervals) within International Normalized Ratio (INR) ranges for randomly selected patients started on, and established on, warfarin treatment for chronic atrial fibrillation. The standard INR range is 2.0 to 3.0 , but there were some individual ranges.

\begin{tabular}{|c|c|c|c|c|}
\hline \multirow[b]{2}{*}{ Treatment intervals (INR) } & \multicolumn{3}{|c|}{ Started on warfarin $(\mathbf{N}=25)$} & \multirow{2}{*}{$\begin{array}{l}\text { Established on warfarin } \\
(\mathbf{N}=\mathbf{2 4 )}\end{array}$} \\
\hline & Ist month & $2^{\text {nd }}$ month & $3^{\text {rd }}$ month & \\
\hline Super therapeutic $(>3.0)$ & $17.0(7.9-26.1)$ & | 4.4 (6.6-22.2) & $9.9(1.3-18.5)$ & $18.8(8.0-29.7)$ \\
\hline Therapeutic $(2.0-3.0)$ & $54.2(42.1-66.4)$ & $66.9(54.3-79.7)$ & $75.4(61.1-89.8)$ & $70.2(59.9-80.4)$ \\
\hline Sub therapeutic $(<2.0)$ & $28.7(15.8-41.5)$ & $18.6(6.7-30.5)$ & $14.6(2.3-27.0)$ & $11.0(4.2-17.8)$ \\
\hline
\end{tabular}

ing a total of 281 PT monitoring episodes were collected (during the patients' first three months of treatment). PT values were monitored on average 3.8 times per month. The individual range for INR values was 2.0 to 3.0 for 24 of the patients, while one had a lower range (1.6 to 2.5). The proportion of time within the therapeutic range was $54.2 \%$ and $75.4 \%$ the first and the third months of treatment, respectively (Table 2). A value associated with a high bleeding risk (INR > 6.0) was found in one episode.

\section{Discussion}

In this study we investigated warfarin treatment for CAF in PHC with regard to occurrence and quality of anticoagulation control. We found that CAF was common among the elderly in primary health care. It appears to be underdiagnosed, and it may also be under-treated. The quality of anticoagulation control with warfarin may only be improved to a limited extent. It was feasible to study warfarin treatment for CAF by reusing information in electronic patient records, although retrieving INR values required a manual review.

The prevalence figures for CAF in our study $(0.6 \%$, and $3.4 \%$ in $65+)$ are lower than in the studies mentioned above $(0.9-1.2 \%$, and $4.7-5.9 \%$ in $65+$ ) [1-3], especially in patients 75 years or older, where our figures are significantly lower. This suggests that there may be an underdiagnosis of CAF in our study, or a selection bias in the types of patients seen in PHC. Our figures represent the prevalence in PHC (e.g. patients who actually were seen in PHC and were treated for CAF) during the one-year study period, and therefore are most probably underestimates of the prevalence in the registered population. The relationship we found between prevalence and age is in accord with findings in similar studies $[1-3,20]$. The prevalence of patients treated with warfarin for CAF has differed somewhat in studies done in recent years. Our figure corresponds well with findings from other Swedish studies ranging from $0.3-0.4 \%[10,15]$, and from a Finnish study where the reported prevalence was $0.3 \%$ [23].
The proportion treated with warfarin $(50.4 \%)$ in our study can be considered intermediate as compared with studies mentioned above (29-97\%) [2,16-18]. However, considering the proportion of CAF patients who are found eligible for warfarin treatment $(41-61 \%)[3,20]$ and, on the other hand, the proportion of patients with contraindications for warfarin (11-18\%) [21,22], our figures suggest a minor underuse. The declining use of warfarin with older age was somewhat more marked in our study compared to findings in similar studies $[2,16]$. Numerous barriers to warfarin treatment still exist in clinical practice, even for eligible patients. These include practical, patientphysician- and healthcare system-related barriers [30], among which a major factor seems to be patients' unwillingness to take warfarin [31]. Our figures may therefore approach what can be achieved in everyday clinical practice. However, the extent to which these figures can be improved is uncertain, since the number of eligible patients is not known in our study. Further improvements should probably include new approaches to CAF treatment such as screening, disease-management teams in PHC, and new strategies for patient education. These need to be supported by the implementation of guidelines, and by new incentives and a health care policy that solve the problem of an increased clinical workload. The number of patients on warfarin treatment and their frequent health care contacts in PHC, a mean of more than once a month in our study, point out a considerable workload related to warfarin treatment, and this has received little attention.

Regarding the INR values, the quality of anticoagulation control can be considered fairly high. The figures were somewhat lower when initiating treatment, as expected. Our figures on monitoring episodes within the therapeutic range $(71.5 \%)$ are in line with or are higher than figures reported in recent studies [23-26]. The proportion of time spent in the therapeutic range $(70.2 \%)$ is higher than the figures mentioned above $(47-51 \%)[27,22]$. These figures may be improved further, as shown by the special anticoagulation clinics [7], but probably only to a very limited degree. This would requires a more organised approach to anticoagulant management including com- 
puter dosing systems and improved systems for follow-up [32].

The major limitations of this study are that it is rather small, the lack of clinical features regarding potential contraindications to anticoagulation, and the lack of information about the presence or absence of risk factors for stroke. An evaluation including the safety of warfarin treatment in PHC would require a longer observation time and a larger sample of patients than in this study. Further, the study was conducted locally, and although we tried to compensate for local variations, conclusions about PHC in general must be made with caution. There is no reason to believe that patients on warfarin treatment were missed, as all patients receiving treatment (as defined above) at the PHC centres are registered under INR values in the laboratory module of the record systems. The actual therapeutic range for the patient is an important factor, as it is sometimes individualised in clinical practice, and this was taken into consideration in our study. Most earlier studies are not based on PHC with a registered population, a representative sample of patients, and records from everyday clinical practice, which are the advantages of our study.

\section{Conclusions}

CAF is common among the elderly in primary health care, and about half of these patients are treated with warfarin. It appears to be under-diagnosed, and may also be undertreated. About two thirds of the treatment time is spent within the therapeutic range, and a further improvement of the quality of anticoagulation control with warfarin treatment may therefore be hard to achieve. Given the frequent monitoring episodes, there is a considerable workload related to warfarin treatment for CAF, both for patients and for care providers.

\section{Competing interests}

The study was supported by grants from the Stockholm County Council and AstraZeneca Sverige AB. IB was a health economist at AstraZeneca Sverige $\mathrm{AB}$ at the time the study was performed.

\section{Authors' contributions}

GHN participated in the design and coordination of the study, performed the statistical analysis and drafted the manuscript. IB participated in the design and coordination of the study and drafted the manuscript. All authors read and approved the final manuscript.

\section{Acknowledgements}

We thank all the GPs who participated in the study: Katarina Eckerbom, Peter Homann, Åke Johansson, the late Olle Wikblad, and Jan-Olov Östling. We also thank Hans Johnsson who participated in the design of the study, and Jonas Carlsson who participated in the statistical analysis.

\section{References}

I. Feinberg WM, Blackshear JL, Laupacis A, Kronmal R, Hart RG: Prevalence, age distribution, and gender of patients with atrial fibrillation. Analysis and implications. Arch Intern Med 1995, I 55:469-473.

2. Majeed A, Moser K, Carroll K: Trends in the prevalence and management of atrial fibrillation in general practice in England and Wales, 1994-1998: analysis of data from the general practice research database. Heart 200I, 86:284-288.

3. Sudlow M, Thomson R, Thwaites B, Rodgers H, Kenny RA: Prevalence of atrial fibrillation and eligibility for anticoagulants in the community. Lancet 1998, 352:1167-II7I.

4. Hart RG, Benavente O, McBride R, Pearce LA: Antithrombotic therapy to prevent stroke in patients with atrial fibrillation: a meta-analysis. Ann Intern Med 1999, I 3 I:492-50 I.

5. Lightowlers S, McGuire A: Cost-effectiveness of anticoagulation in nonrheumatic atrial fibrillation in the primary prevention of ischemic stroke. Stroke 1998, 29:1827-1832.

6. Samsa GP, Matchar DB: Relationship between test frequency and outcomes of anticoagulation: a literature review and commentary with implications for the design of randomized trials of patient self-management. J Thromb Thrombolysis 2000, 9:283-292.

7. Ansell J, Hirsh J, Dalen J, Bussey H, Anderson D, Poller L, Jacobson A, Deykin D, Matchar D: Managing oral anticoagulant therapy. Chest 200I, I I 9:22S-38S.

8. Hylek EM, Go AS, Chang Y, Jensvold NG, Henault LE, Selby JV, Singer $D E$ : Effect of intensity of oral anticoagulation on stroke severity and mortality in atrial fibrillation. N Engl J Med 2003, 349:1019-1026.

9. Hutten BA, Prins MH, Redekop WK, Tijssen JG, Heisterkamp SH, Buller HR: Comparison of three methods to assess therapeutic quality control of treatment with vitamin $K$ antagonists. Thromb Haemost 1999, 82: I260-1263.

10. Wändell PE: A survey of subjects with present or previous atrial fibrillation in a Swedish community. Scand J Prim Health Care 200I, 19:20-24.

II. Eskola K, Aittoniemi P, Kurunmaki H, Latva-Nevala A, Paloneva M, Wallin AM, Viitaniemi M, Virjo I, Ylinen S, Ohman S, Isokoski M: Anticoagulant treatment in primary health care in Finland. Scand J Prim Health Care 1996, I4:165-I70.

12. Palareti G, Leali N, Coccheri S, Poggi M, Manotti C, D'Angelo A, Pengo V, Erba N, Moia M, Ciavarella N, Devoto G, Berrettini M, Musolesi S: Bleeding complications of oral anticoagulant treatment: an inception-cohort, prospective collaborative study (ISCOAT) Italian Study on Complications of Oral Anticoagulant Therapy. Lancet 1996, 348:423-428.

13. Poller L, Shiach CR, MacCallum PK, Johansen AM, Munster AM, Magalhaes A, Jespersen J: Multicentre randomised study of computerised anticoagulant dosage. European Concerted Action on Anticoagulation. Lancet 1998, 352:1505-I 509.

14. Kalra L, Yu G, Perez I, Lakhani A, Donaldson N: Prospective cohort study to determine if trial efficacy of anticoagulation for stroke prevention in atrial fibrillation translates into clinical effectiveness. BMJ 2000, 320: I 236- I 239.

15. Wändell PE: Anticoagulant patients in Swedish primary health care. A comparison 5 years apart. Scand J Prim Health Care 1998, 16:183-187.

16. Go AS, Hylek EM, Borowsky LH, Phillips KA, Selby JV, Singer DE: Warfarin use among ambulatory patients with nonvalvular atrial fibrillation: the anticoagulation and risk factors in atrial fibrillation (ATRIA) study. Ann Intern Med 1999, I 3 I:927-934.

17. Ceresne L, Upshur RE: Atrial fibrillation in a primary care practice: prevalence and management. BMC Fam Pract 2002, 3: I I.

18. Hover AR, Rogers JT, Hunt C: A comparison of rural and urban anticoagulation management of atrial fibrillation in a southwest Missouri health system. Mo Med 2003, 100:94-97.

19. Frykman V, Beerman B, Ryden L, Rosenqvist M: Management of atrial fibrillation: discrepancy between guideline recommendations and actual practice exposes patients to risk for complications. Eur Heart J 200I, 22:1954-1959.

20. Wheeldon NM, Tayler DI, Anagnostou E, Cook D, Wales C, Oakley GD: Screening for atrial fibrillation in primary care. Heart 1998, 79:50-55.

21. Filippi A, Bettoncelli G, Zaninelli A: Detected atrial fibrillation in north Italy: rates, calculated stroke risk and proportion of 
patients receiving thrombo-prophylaxis. Fam Pract 2000, 17:337-339.

22. Samsa GP, Matchar DB, Goldstein LB, Bonito AJ, Lux LJ, Witter DM, Bian J: Quality of anticoagulation management among patients with atrial fibrillation: results of a review of medical records from 2 communities. Arch Intern Med 2000, 160:967-973.

23. Viitaniemi M, Eskola K, Kurunmaki H, Latva-Nevala A, Wallin AM, Paloneva M, Virjo I, Ylinen S, Ohman S, Isokoski M: Anticoagulant treatment of patients with atrial fibrillation in primary health care. Scand J Prim Health Care 1999, 17:59-63.

24. Fitzmaurice DA, Hobbs FD, Murray ET: Primary care anticoagulant clinic management using computerized decision support and near patient International Normalized Ratio (INR) testing: routine data from a practice nurse-led clinic. Fam Pract 1998, I5: | 44- | 46.

25. Wändell PE: Anticoagulant treatment of patients in Swedish primary health care. Eur J Clin Pharmacol 200I, 57:6I-64.

26. Yermiahu T, Arbelle JE, Shwartz D, Levy Y, Tractinsky N, Porath A: Quality assessment of oral anticoagulant treatment in the Beer-Sheba district. Int J Qual Health Care 200I, I3:209-2 I 3.

27. McCormick D, Gurwitz JH, Goldberg RJ, Becker R, Tate JP, Elwell A, Radford MJ: Prevalence and quality of warfarin use for patients with atrial fibrillation in the long-term care setting. Arch Intern Med 200I, 16I:2458-2463.

28. Cobbe SM: Using the right drug. A treatment algorithm for atrial fibrillation. Eur Heart J 1997, 18:C33-C39.

29. Hutten BA, Prins MH, Redekop WK, Tijssen JG, Heisterkamp SH, Buller HR: Comparison of three methods to assess therapeutic quality control of treatment with vitamin $\mathrm{K}$ antagonists. Thromb Haemost 1999, 82: 1260-1263.

30. Buckingham TA, Hatala R: Anticoagulants for atrial fibrillation: why is the treatment rate so low? Clin Cardiol 2002, 25:447-454.

31. Howitt A, Armstrong D: Implementing evidence based medicine in general practice: audit and qualitative study of antithrombotic treatment for atrial fibrillation. BMJ 1999, 3 18:1324-1327.

32. Taylor FC, Ramsay ME, Renton A, Cohen H: Methods for managing the increased workload in anticoagulant clinics. BMJ 1996, 3 I 2:286.

\section{Pre-publication history}

The pre-publication history for this paper can be accessed here:

http://www.biomedcentral.com/1472-6904/4/1/prepub
Publish with Biomed Central and every scientist can read your work free of charge

"BioMed Central will be the most significant development for disseminating the results of biomedical research in our lifetime."

Sir Paul Nurse, Cancer Research UK

Your research papers will be:

- available free of charge to the entire biomedical community

- peer reviewed and published immediately upon acceptance

- cited in PubMed and archived on PubMed Central

- yours - you keep the copyright
BioMedcentral 